\title{
GUERREIRO JUNIOR, Antônio Roberto. 2015. Ancestrais e suas sombras: uma etnografia da chefia Kalapalo e seu ritual mortuário. Campinas: Editora da Unicamp. 520 pp.
}

\author{
THAÍS REGINA MANTOVANELLI
}

Entre os Kalapalo, segundo Guerreiro Júnior, a expressão em português que se refere à aprendizagem pode ser traduzida como "abrir os olhos", um processo que depende, por sua vez, da penetração da verdadeira fala nas orelhas daquele que se dispõe a aprender algo. A narrativa etnográfica desenvolvida pelo autor não só levou em consideração o entendimento Kalapalo acerca do processo de aprendizagem, uma abertura dos olhos por meio da penetração auricular da fala correta, como investiu na elaboração de imagens conectadas que se relacionam com a questão da chefia e sua extensão ao conceito de gente e a formação dos grupos de parentes.

O autor deixou seus olhos serem abertos pelo povo Kalapalo e essa visualidade de extrema importância para o processo ritual de produção de chefes, pessoa, parentes e aldeias foi tornada por ele uma ferramenta fundamental de sua descrição e análise.

A aposta narrativa de Guerreiro Júnior consistiu em não corroborar com teorias antropológicas explicativas e/ou informativas sobre um povo, um coletivo e suas práticas que tendem a tomar os efeitos pelas causas. Não se trata, portanto, de uma descrição monográfica que tem como objetivo informar sobre algo, mas sim de um esforço narrativo, epistemológico e político de imprimir ao texto uma forma inspirada na própria realização do grande ritual xinguano conhecido como Quarup e chamado pelos Kalapalo, povo com quem o autor realiza seus trabalhos de pesquisa, de egitsü.

Segundo Marcela Coelho de Souza, no prefácio que inaugura o livro, a descrição do ritual ou "festa dos mortos" assume um importante modo de visibilização dos povos xinguanos do PIX (Parque Indígena do Xingu), um epítome da cultura do Alto Xingu cujo um dos efeitos é a veiculação da imagem desses coletivos como povos vizinhos politicamente autônomos que afirmam sua habilidade de conviver pacificamente por meio da performance ritual.

A opção do autor em retratar etnograficamente a chefia a partir da realização e do preparo do ritual mortuário xinguano compõe um caminho inovador acerca do modo como as relações de chefia ameríndia podem ser descritas. Nesse aspecto, o livro oferece um modo criativo para o tratamento das relações entre os chefes e as coletividades que se associam a eles, possibilitando a leitura de uma teoria 
etnográfica da política xinguana apresentada por meio das formas pelas quais a chefia é (re)conhecida e produzida pelos Kalapalo.

A narrativa etnográfica de Guerreiro Júnior tem como ponto alto de sua metodologia a não transposição de conceitos caros às ideologias políticas da modernidade ocidental como a associação entre chefes, representantes, autoridade, hierarquia e poder. Dessa maneira, o etnógrafo volta sua atenção aos modos específicos da cosmopráxis ritual Kalapalo acerca de seus chefes, dos chefes dos grupos vizinhos e da chefia, num sentido mais abrangente. $\mathrm{O}$ efeito dessa abordagem metodológica é a visibilização pelo leitor de um empenho narrativo que se esforça para a reverberação da chamada teoria nativa tanto no conteúdo, quanto na forma da redação textual.

A estratégia adotada permite ao autor escapar dos perigos das descrições óbvias que tomam a chefia como sendo exclusivamente a relação de um chefe com seus coaldeões e com grupos vizinhos ou estrangeiros.

Dessa maneira, a forma-chefe vai sendo apresentada ao longo do livro como uma estabilização ou cristalização que nunca se fixa ou se totaliza enquanto uma entidade suprema e transcendental. Ao eleger esse caminho metodológico, os processos de aglutinação e desaglutinação de pessoas em volta de um chefe vão tomando dimensões importantes, sendo retratados como "feitos em ato", para mencionar uma expressão wagneriana. Em outras palavras, tais processos aparecem sem que uma teoria prévia seja sobrepujada aos dados etnográficos.

O livro apresenta a constituição da política kalapalo como ação, para remeter a conceitos utilizados por Deleuze e Guattarri no Miles Plateaux (1980). Os filósofos propõem discutir a antropologia política clastreana, inspirada na conceituação das "sociedades contra-Estado", por meio de operações do que nominam como "máquina de guerra". Nas proposições defendidas pelos autores, máquinas de guerra ou o "contra o Estado" podem coexistir com o Estado no entrelaçamento de linhas de segmentaridade e linhas de fugas que se atualizam e se distanciam incessantemente.

Assim, ao tomar a constituição da chefia e dos coletivos Kalapalo como ação, o autor imprime atenção às minúcias das formas pacíficas das políticas xinguanas, destacando também seus nexos regionais, nacionais e internacionais sem cair no discurso fracionado dos graus de contato das sociedades indígenas segundo suas relações de dependência com as sociedades dos brancos. Tal opção também promove o afastamento de cálculos que separam os ditos modos tradicionais indígenas das perdas culturais ou de processos de aculturação por meio da introdução contaminadora de elementos exógenos.

Dessa maneira, a descrição da realização da forma-chefe kalapalo, no ato de suas feituras rituais e cotidianas, engrossa o debate sobre os efeitos da presença massiva dos brancos de maneira a não os identificar de antemão como elementos de deformação das formas políticas ameríndias.

Por meio de sua descrição e análise, o autor problematiza também a suposta fixidez que o conceito "identidade étnica" tende a imprimir aos coletivos ameríndios. Uma fixidez que não condiz com os modos Kalapalo de produção de coletivos e grupos e que oblitera a associação dos povos xinguanos como efeitos de relações regionais entre outros povos e com os brancos, o que caracteriza uma ênfase nas relações e não nos termos. Nas palavras do autor, é importante que a operação descritiva considere simultaneamente dois lados da questão sobre a formação de coletivos, levando em conta tanto o "lugar 
dos chefes na produção da história coletiva xinguana", quanto o "lugar da história coletiva na produção dos chefes" (:71, itálicos no original).

A etnografia de Guerreiro Júnior apresenta uma possibilidade metodológica dinâmica acerca dos procedimentos analíticos pertinentes para os casos de descrição de sistemas regionais como ocorre entre os grupos xinguanos multilíngues do PIX e entre os grupos das famílias linguísticas tukano, arawak, maku que compõem o sistema de troca e exogamia linguística rio negrino.

Engajado com o léxico Kalapalo acerca de chefia e seus processos de constituição, por meio da substituição dos chefes mortos por chefes vivos, o autor visibiliza a importância do idioma vegetal arbóreo como expressiva referência para a fabricação da pessoa e dos chefes. Terminologias como iho, traduzida como esteio, e ihü, tronco-corpo, são de suma importância para o entendimento da chefia e das relações de parentesco. O conceito metassemântico iho, traduzido como arrimo ou esteio, é a palavra usada pelos Kalapalo para se referirem ao poste de madeira onde se amarra uma rede, e ao mesmo tempo ao dono de uma casa que cuida das pessoas que moram nela. A expressão designa relações de cuidado, proteção e suporte. Os chefes são descritos como "esteio de gente" (:169) e devem sustentar a aldeia, assim como os postes de sustentação de uma casa a mantém de pé. Essa sustentação é realizada por meio de ações de generosidade e cuidado, compelindo os moradores de uma aldeia a quererem viver juntos. O chefe é pensado então como esteio ou corpo-tronco do seu grupo, uma pessoa sem a qual as demais não se manteriam em pé.

A ideia de suporte perpassa também o conceito de raiz [intsü]. Termo que traduz certas relações de parentesco, de chefia e de conhecimento. Os avós são as raízes de uma criança, assim como seu pais que cuidam dela. Do mesmo modo, os mestres das histórias são raízes de suas narrativas, pois precisam cuidar delas para contá-las de modo correto. Nas palavras do autor, a importância do idioma vegetal arbóreo pode ser expressa por meio da relação do chefe como "um tronco que sustenta o crescimento de um corpo de parentes, assim como é um esteio sobre o qual as pessoas se apoiam” (:173). Pessoas que brotam das mesmas raízes, que compartilham pais e avós, estão diretamente associadas à continuidade dos chefes que brotam uns dos outros.

A relação entre o idioma vegetal arbóreo, a chefia e a consanguinidade marca de modo significativo os processos de formação de chefes, que são os substitutos de seus antecessores. Importante salientar que, segundo Guerreiro Junior, o conceito de chefe como esteio, alicerce ou eixo, não implica a cristalização dessa noção como algo absoluto ou totalizador. A relação de cuidado e proteção que cabe ao dono ou chefe é replicada em todas as escalas, de forma fractal não totalizante e sua posição depende da relação que se está visibilizando numa dada situação. Nesse sentido, o autor fornece uma análise original acerca da questão da transmissão da chefia entre os Kalapalo que questiona a precedência de uma hierarquia pronta a ser obedecida por meio da hereditariedade e da ordem de nascimento dos filhos. O tema da ascendência nobre ou do sangue do chefe é analisado etnograficamente como uma relação necessária, mas não suficiente para o exercício da chefia.

O sangue é tomado como um idioma de relações e não como uma substância transmitida fisiologicamente entre parentes consanguíneos. Não basta que uma pessoa tenha sangue de chefe para se tornar um chefe. Um chefe precisa ser feito pelas pessoas de seu grupo e por chefes de grupos vizinhos 
ou estrangeiros. Assim, a questão da transmissão da chefia e da importância do sangue de chefe não é tomada como decorrente das relações de origem de nascimento, mas, sobretudo, como decorrente de relações com outros chefes. Além disso, uma pessoa precisa desenvolver certas características para se tornar chefe, como dominar uma capacidade oratória excelente de fala tranquila e humilde, ser generosa e não transparecer fúria ou raiva.

Além da relevância do idioma vegetal arbóreo para a descrição da chefia, Guerreiro Júnior também destaca que existe um idioma de predação associado à produção dos chefes. Entretanto, diferentemente do que ocorre em outras paisagens ameríndias, como entre os povos das chamadas cosmologias Tupi Guarani, a relação de predação concernente à chefia não supõe a existência de uma presa. A visibilização da figura do chefe como predador é expressa ritualmente e exclusivamente na relação com outro chefe, que também é um predador (não-presa), destacando uma inimizade ritual que é obliterada por relações de troca e disputas competitivas como a luta xinguana conhecida como buka-buka, chamada pelos Kalapalo de ikindene.

Por meio dessa especificidade das relações rituais de predação, o pacifismo ritual xinguano é tratado pelo autor, em um ponto central de sua argumentação, como uma transformação do idioma da guerra e da função guerreira e como um importante elemento da socialidade entre os xinguanos e os brancos.

Devido à riqueza da descrição do autor, retratar todas as nuances e detalhes do processo de formação dos chefes a partir do ritual mortuário xinguano torna-se uma tarefa árdua. Por esse motivo, a intenção desta resenha foi antes considerar o empenho narrativo do autor em dar destaque às formas de expressão e ação consideradas importantes e eficazes para as pessoas com quem ele estabeleceu relações de pesquisa, amizade e parceria. Tarefa ética e política que manteve presente em seus esforços para que seus olhos pudessem manter-se abertos e atentos a outros modos de ação política, que não tenham como fundamentos os arcabouços da ideologia moderna ocidental.

Thais Regina Mantovanelli é mestre e doutora em Antropologia pelo PPGAS/ UFSCar.

RECEBIDO: 09/03/2017

APROVADO: $10 / 05 / 2017$ 